\title{
PERCEIVED DISTRIBUTIVE JUSTICE OF SERVICE RECOVERY AND POST- RECOVERY SATISFACTION: A STUDY OF DOMESTIC AIRLINE CUSTOMERS IN SOUTH WEST NIGERIA
}

\author{
Ogunode Philips Olatunde and Prof. (Ven.) A. D. Nkamnebe \\ Department of marketing, Nnamdi Azikiwe University, Awka, Anambra State, Nigeria. \\ Correspondence E-mail: philips29g@yahoo.com
}

Cite this article:

Ogunode P.O., Nkamnebe A.D. (2021), Perceived Distributive Justice of Service Recovery and Post-recovery Satisfaction: A Study of Domestic Airline Customers in South West Nigeria. British Journal of Management and Marketing Studies 4(3), 39-50. DOI: 10.52589/BJMMS4IRH9XIV.

\section{Manuscript History}

Received: 5 June 2021

Accepted: 25 July 2021

Published: 20 July 2021

Copyright $(2020$ The Author(s). This is an Open Access article distributed under the terms of Creative Commons AttributionNonCommercial-NoDerivatives 4.0 International (CC BY-NC-ND 4.0 ), which permits anyone to share, use, reproduce and redistribute in any medium, provided the original author and source are credited.
ABSTRACT: This study examined perceived distributive justice of service recovery and post-recovery satisfaction: a study of domestic airline customers in south west Nigeria. The study adopted the perceived justice theory to service recovery with the three dimensions of justice underpinning the study's conceptual framework/research model. Quantitative research design was employed. The unit of analysis comprised of domestic airline customers in south west geopolitical zone of Nigeria. Quota and purposive sampling were the sampling techniques and a sample of 1,998 respondents was statistically drawn using Cochran. Questionnaire was the research instrument; exploratory factor analysis through principal component extraction method was used to statistically measure construct validity while Cronbach Alpha was used to establish the reliability of the instrument. Hypothesized relationships in the path diagram resulting from the research model were tested using Partial Least Square Structural Equation Modeling (PLS$S E M)$ with the aid of $I B M^{\circledR} S P S S^{\circledR} A M O S^{T M} 25$. The finding of this study showed that distributive justice had significant and positive influence on post-recovery satisfaction. It was recommended that airline companies operating in the zone should organize regular training programmes for their staff on how to work with emerging aviation technologies so as to minimize errors and reduce costs that are associated with compensation.

KEYWORDS: Perceived justice, Distributive Justice, Service Recovery, Post-Recovery Satisfaction 


\section{INTRODUCTION}

The airline industry across the globe is known to have great influence in terms of its contribution to the growth and development of many nations. Ensuring the development of a vital sector such as this will fast-track economic growth and generate some economic benefits. According to Chidi and Izuwah (2019), about 254,500 Nigerians and non-indigenes have been gainfully engaged by the Nigeria airline industry and contribute US\$940 million (\#184.7 billion) to national GDP. This is an indication that the sector is germane when it comes to revenue generation through personal income and business taxes. The airline industry plays a vital role in the area of work and leisure to tourists all over the world. The sector also helps promoting and improving the living standard of people within and across nations. This makes the airline industry so crucial to any economy that is willing to develop, pave way for globalization, facilitates trade and tourism development (Ladele, 2012).

In the view of Ladele (2012), as nations develop, the needs for air transportation also increase due to the growth in the citizens' disposable income. This shows that there is great potential for growth in the industry if properly managed.

However, Amba and Danladi (2013) have highlighted some problems which are common to the airline industry which often hinder smooth service delivery. He listed them to include high cost of operation and maintenance, inadequate funding, lack of transparency, poor managerial skills, lateness in responding to emergency occasioned by sudden air mishap and poor service delivery caused by both mechanical and human errors.

Sequel to the numerous gains that accrued to developing nation such as Nigeria from this sector, the industry is best appreciated if effort is geared toward improving the service it provides to its ever-discerning customers in order to minimize any form of service failure that may negatively impact on the growth of the sector.

Due to the complex nature of the airline industry, there is need for synergy among the airport, airline companies and employees to be able provide quality services that can meet passengers' expectation. According to Chang, Chen and Chang (2008), airline companies are confronted with both internal and external disruptions that could trigger service failures. The manner in which service firms respond to a service failure (service recovery) has the the potential of placing an airline at advantage. The way an organisation respond to a service failure could either restore customer satisfaction, increase loyalty, or trigger negative emotion which drive the client to a competitor.

According to Sparks and McColl-Kennedy (2001), service recovery is capable of restoring a dissatisfied customer and makes them develop positive attitude toward the offers of the organization. Also, studies such as McDougall and Levesque (1999) clearly stated that effective service recovery strategies such as assistance plus compensation had great impact on post recovery satisfaction. In another study by Yaya, Marimon and Casadesus (2013), it was discovered that service recovery had a significant effect on customer satisfaction, perceived value and post recovery intention. 


\section{Statement of Problem}

The widespread customer dissatisfaction and rising magnitude of unresolved complaints occasioned by airline service failure in the Nigeria airline industry is the first thing that triggered this study. As reported by Phillips Consulting (2015), the growth in the Nigeria airline industry has resulted in influx of passengers for both local and international destinations exceeding 15 million in 2014. The growth in the sector has continued to mount pressure on airport managers, airline companies, employees and airport facilities. Beside rivalry among airlines, there are problems of satisfying the changing needs of customers. Many airport facilities are not enough, while many airline passengers complain about flight cancellations, missing luggage, poor ticket services, check in rejection, inefficient staff and other related problems which have combined to inhibit efficient service delivery and customer satisfaction in the airline industry.

Secondly, the majority of studies on service recovery to recent times have largely focused attention either on the financial sector, online retailers or restaurant service. On financial sector by Michel, (2001), Chebat and Slusarczyk (2005), Jones and Farquhar (2007), Sousa and Voss (2009), Varela-Neira, Vazquez-Casielles and Iglesias (2010a), (2010b), Komunda and Osarenkhoe (2012), De Matos, Henrique, Vargas and Rossi (2013), Yaya,, Marimon and Casadesus (2013); studies on online retailers include: Lee and Park (2010), Wang and Mattila (2011); on restaurant service include studies by Mattila (1999), Mattila and Patterson (2004), Namkung and Jang (2010a), Susskind and Viccari (2011), Othman, Zahari and Radzi (2014), Park, Kim and O'Neill (2014); and Tsai, Yang and Cheng (2014). Thus, the research on perceived justice of service recovery among airline customers has been inadequate and relatively not much has been done to unravel the influence of perceived distributive justice of service recovery on post recovery satisfaction among airline customers in South West Nigeria.

Similarly, different studies on service recovery strategies have been carried out from different perspectives (Carew, 2010; Park, 2004 and Lowenstein, 1995) and each proffering different strategies that could influence customers' satisfaction (Ahmad, Ghazali and Othman, 2013; Akbar and Alaudeen, 2012; and Zemke \& Bell, 1990). Service recovery strategies ranging from apology (Zemke and Bell, 1990), problem solving (Battaglia, Borchardt, Afonso and Pereira, 2012), open explanation (Conlon and Murray, 1996; Boshoff, 1999), compensation (Boshoff, 1999), follow up (Ennew and Schoefer, 2003), and the findings show varied results; thus, causing and informing different growth policy implications. As noted by Tabassum and Rahman (2012), service recovery strategies may differ as a result of differences in culture, climate, social-economic status, e.t.c. Due to differences in the findings of researchers; it is not yet clear which service recovery strategies influence post recovery satisfaction among domestic airline customers in South-Western Nigeria.

Consequent upon the foregoing, this study specifically examines the influence of perceived distributive justice of service recovery on post recovery satisfaction. It also investigates the comparative influence of demographics on perceived distributive justice of service recovery and post recovery satisfaction. 


\section{REVIEW OF RELATED LITERATURE}

\section{Service Recovery}

Gronroos (1988) defined service recovery as the steps taken by a service provider to tackle complaints by customers concerning service failure. Gronroos' definition was reiterated by Zeithaml, Bitner and Gremler (2009) and Buttle (2009) who see service recovery as the efforts put in place to respond proactively to incidence of service failure. Piyali (2011) view service recovery as the strategies of ensuring that the right things are done right after experiencing something abnormal in service delivery. The trio of Miller, Craighead and Karlvan (2000) in lending their contributions refers to service recovery as the actions deliberately designed by service organisations to tackle problems, change negative attitudes of aggrieved customers and retain them.

The various perspectives of various scholars as cited above bother on organisations' reactions to cases of service failures. It is clear from the definitions above that service recovery involves steps put in place by firms to solve problems after service has been provided (Zeithamal et al 2009; and Buttle 2009) and from unhappy clients who may lodge his/her complaint after encountering unpleasant services (Gronroos, 2008; Johnston and Michel, 2008; Miller, Craighead and Karwan, 2000 and Hart, Heskett and Sasser, 1990). From the cited definitions, it is clear that cases of service failure are unavoidable and that organisations must put measures in place to tackle complaints as they occur so as to ensure service recovery management. Also, it shows that service recovery efforts should be established by companies after the incidence of service failure. It is vivid from these enormous definitions that frantic step is required to take sufficient effort to proffer solutions to varieties of problems facing organisations after service failure. These pools of definitions indicate that service recovery should be seen as been a reactive effort which is only introduced when failures surfaces. The definitions should have also viewed service recovery as a pro-active effort where deliberate actions are taken to prevent failure from occurring or will be tackled at the emerging stage (Skinner et al 2008; and Meuter and Michel, 2008) instead of exhibiting care free attitude which may be too costly for the organization in its effort to recover aggrieved customers. Adding to the diverse definitions of service recovery, Miller et al (2000) see it as situations even where if no complaint is lodged. This strategy is used by most sensitive organisations that have zero tolerance service failures as they try to unearth failure cases ever before it gets to the notice of customers.

Sequel to the arrays of definitions from different school of thoughts, this study has adopted the definition of service recovery by Zeithaml et al (2009). To this end, the adopted definition of service recovery for this study is "the measures put in place by firms to disallow and react quickly to service failure".

\section{Distributive Justice}

The term distributive justice is separated from the social trade theory which states the pertinence of justice in choosing clients' future exchanges (Adams, 1963). The fundamental advocate of distributive justice is equity theory (Pinder, 1998) which is of the view that that an individual analyzes the proportion of his/her own outcome to enter with the proportion of other's outcome (Adams, 1963). Equity is said to have occurred when the proportion of an individual's outcome to include is equivalent to the proportion of the reference source. 
Inequity exists when the proportion of an individual's outcome to include varies to a huge degree from the proportion of outcome to enter apparent for the reference source (Miner, 1980).

In equity theory, clients are supposed to be fulfilled when the outcome to-include proportion of an individual is more prominent than that of others. Alternately, when somebody's outcome to-include proportion is not exactly a reference source's outcome to-enter proportion, at that point clients experience dissatisfaction. Equity theory isn't restricted to injustice that damages individuals; there is likelihood that the injustice may give them a benefit. This shows that inequity isn't generally negative; it could have a positive angle also. An individual who has encountered adverse injustice will feel under compensated, and an individual who has encountered positive injustice will feel over remunerated. A person who feels over or under remunerated will feel inequity. In any case, individuals will in general amplify their outcome despite the fact that they know about inequity. At the point when a client experience inequity, it could additionally lead them to a condition of dissatisfaction. Dissatisfaction could be seen as outrage for being undervalued or coerce for being over remunerated (Miner, 1980).

As McCollough, Berry and Yadav (2000) have it, distributive justice and interactional justice end up being significant indicators for post-recovery satisfaction. Flash and McColl-Kennedy (2001) in their examination showed that perceived justice (distributive, procedural, and interactional) has critical impact on consumer loyalty in a lodging setting. Same view was shared by Holbrook Jr. also, Kulik (2001); their exploration set up that justice is significant in understanding a client's response with regards to an assistance. This current study is aim at establishing the influence of perceived justice of service recovery on post recovery satisfaction in the airline industry.

As noted earlier, a number of perceived justices of service recovery studies have empirically proven that perceived distributive justice of service recovery will enhance customer satisfaction. For instance, studies by McCollough, Berry and Yadav (2000) have empirically shown that distributive justice and interactional justice are strong indicators for post-recovery satisfaction. Spark and McColl-Kennedy (2001) established the correlation between perceived justice (distributive, procedural, and interactional) and customer satisfaction in the hospitality sector. Similar opinion was shared by Holbrook Jr. and Kulik (2001); their studies showed that justice is essential in knowing a consumer's response in a service setting. It is therefore well established in extant service recovery literature that perceived justice of service recovery is a key factor and predictor for post recovery satisfaction. Thus we hypothesize as follows:

$\mathrm{H}_{1}$ : Perceived distributive justice of service recovery will positively influence post recovery satisfaction.

\section{Theoretical Perspective}

This study is anchored on justice theory because of it adequacy in measuring perceived justice of service recovery. The theory is on the three components of justice which are: distributional justice, procedural justice, and interactional justice (Blodgett et al., 1993; Clemmer and Schneider, 1996; Smith et al., 1999; Tax et al., 1998). More so, the theory was considered appropriate because majority of the studies on service recovery have often found 
justice very suitable (Solomon, 2004; Schiffman and Kanuk, 2007; Rio-Lanza et al., 2008). More importantly, this theory aligns significantly with the present study due to it perspective and it reflection of perceived justice of service recovery.

\section{Materials and methods}

This current study was conducted using the survey method. A significant sensible number of service recovery contemplates that have utilized study technique includes Ellywati and Purwanto (2012), Nikbin et al. (2010), Nek Kamal (2009), (Nikbin et al., 2010), Cho (2013), Mansori, Tyng, and Ismail (2014), Kim, Kim, and Kim (2009), and; Chang and Chang (2010).

This research was executed in the South West geopolitical zone of Nigeria. Specifically, the study areas include Lagos, Oyo and Ondo states. These three states were used because they are the three (3) states within the south west with functional airports. The aggregate of individual person or object for investigation, or the totality of the units of analysis is called the study population (Okeke, et al,. 2012). The population of this research comprised of domestic airline customers in South-West geo-political zone of Nigeria. Hence, focus was on the three airports in the zone (that is, Murtala Mohammed International airport, Ikeja, Lagos state; Akure airport, Ondo state and Ibadan airport, Oyo state). Thus, the population of study is unknown since we cannot ascertain the number of domestic airline customers who have experienced service failure with exactitude through a secondary source. This study employed both quota and purposive sampling techniques. Quota sampling was to ensure that respondents from the various demographic attributes partake in the sample. Quota sampling aims at ensuring that the selection of potential respondents is based on some pre-specified quotas for either demographic characteristics or certain behaviours through disproportionately (Okeke and Eze, 2012).

The number of airline customers in the south west geopolitical zone who have encountered service failure is unknown. Due to this, Cochran's formular for calculating sample from unknown population was used following the yardsticks (Tull and Hawkins, 1993): allowable error margin $\left(\mathrm{e}^{2}\right)$, level of confidence to be obtained $\left(\mathrm{z}^{2}\right)$ and an estimated variance for the population $\left(\underline{\alpha}^{2}\right)$. Therefore, the formula used in determining the sample size was:

$$
\mathrm{n}=\frac{\mathrm{z}^{2} \alpha^{2}}{\mathrm{e}^{2}}
$$

As indicated by Field (2009), the coefficient Z., for a 95\% degree of certainty is 1.96 and as per Tull and Hawkins (1993), the change $\alpha^{2}$ for a 5 point Likert scale, is 1.3. A five point interval Likert scales was utilized to quantify the perceived justice of service recovery and post recovery satisfaction. Therefore, the sample size for this research is statistically calculated as follows: 


$$
\mathrm{n}=\frac{1.96^{2} 1.3}{0.05^{2}}=1,998
$$

A sample size of 1,998 airline customers was purposively selected from the three locations in this order: Murtala Mohammed International airport, Ikeja (1,400); Akure airport (249) and Ibadan airport (349). The instrument used for collecting primary data is the questionnaire. Moody (2012) sees questionnaire as a document that contain series of questions or statements that are meant to elicit responses from the selected respondents .

Exploratory Factor Analysis (EFA) through principal component extraction method was used to statistically measure construct validity of the instrument. The factor loading of the items were used to ascertain the Average Variance Extracted (AVE). The KMO and the Barlett test were utilized to decide the adequacy of the sample size. As indicated by Kaiser (1974), if the result of the Kaiser-Meyer-Olkin (KMO) is greater than 0.5, this implies that the question really measured the variables of the study. Additionally, Cronbach's Alpha method of reliability was used to establish the reliability of the instrument. The researcher administered the instrument on 50 respondents who were not part of the target sample. The scores obtained were subjected to statistical analysis using Cronbach's Alpha statistics at 0.05 level of significance. Reliability coefficients of 0.722 and 0.957 were obtained on "perceived distributive justice and post recovery satisfaction "subscales respectively while the overall reliability coefficient was 0.957 .

Partial Least Square Structural Equation Modeling (PLS-SEM) with the aid of Smart PLS software was used to test and confirm interrelationship among the variables posited by the conceptual framework and to ensure goodness of fit to the conceptual model.

\section{RESULTS}

Research Hypothesis: Perceived distributive justice of service recovery will positively influence post recovery satisfaction.

Figure 1 displays the path diagram and standardized estimates of the influence of perceived distributive justice on post recovery satisfaction. Gender, age, income and travel frequency were specified as control variables. 


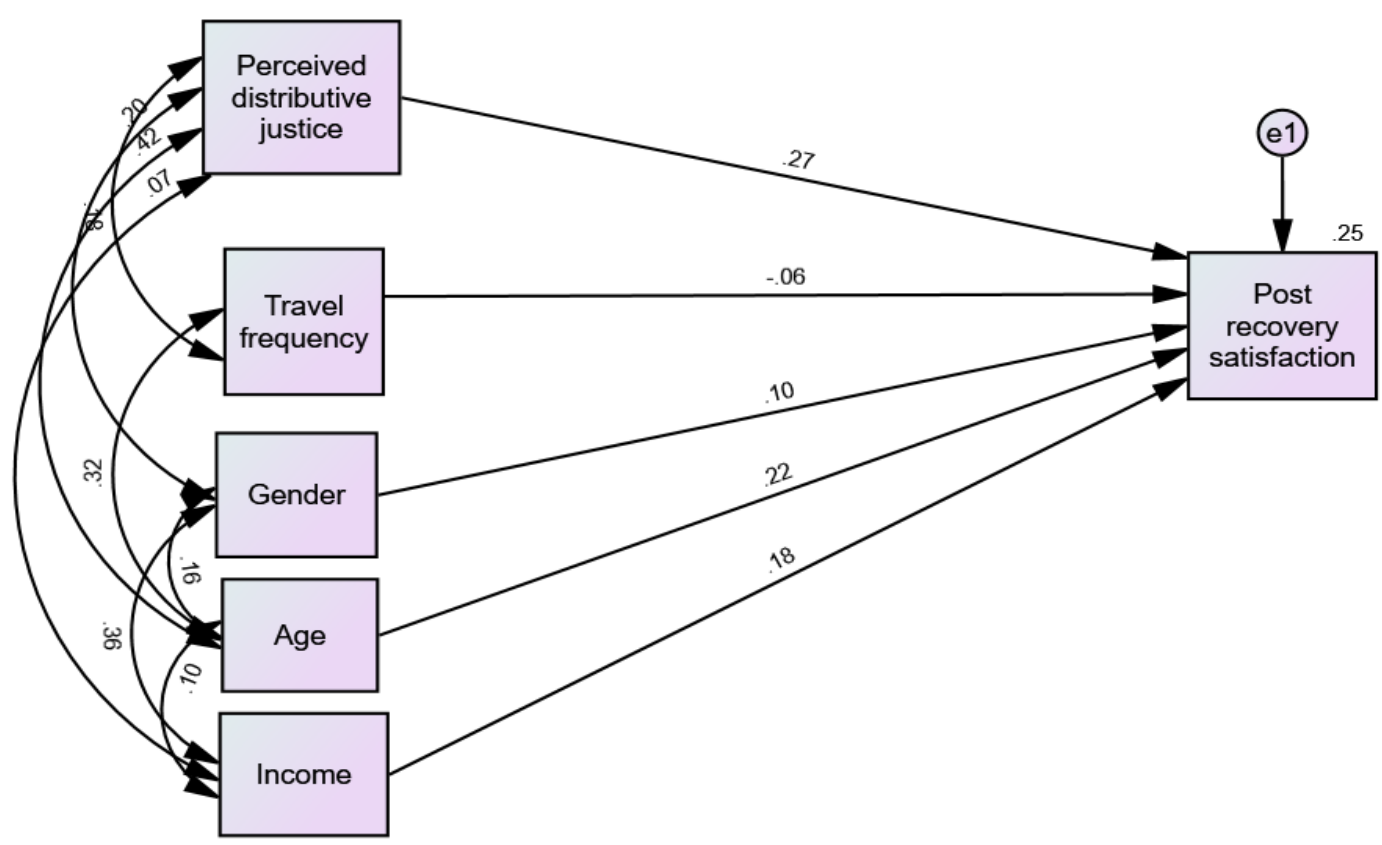

Figure 1: Direct influence of perceived distributive justice on post-recovery satisfaction controlling for socio-demographic variables

Table 4.12 shows the results of path analyses with $p$-values. The model fit was absolute, $\chi^{2}$ $(2)=.02, \mathrm{p}=.87 ; \mathrm{CFI}=1.00 ; \mathrm{RMSEA}=.00[90 \% \mathrm{CI}=(.00, .03)], \mathrm{SRMR}=.00$. Outcomes show that perceived distributive justice was significant on post-recovery satisfaction $(\beta=.27$, $p<.001)$. Specifically, an increase in perceived distributive justice predicted an increase in post-recovery satisfaction. The control variables, gender $(\beta=.10, p<.001)$, age $(\beta=.22, p<$ $.001)$, income $(\beta=.18, p=.009)$ and travel frequency $(\beta=-.06, p=.005)$ were significant on post-recovery satisfaction. Specifically, being a female, older, having a higher income and lower travel frequency were associated with post-recovery satisfaction. The model explained $25 \%$ variance in post-recovery satisfaction.

Table 1: Direct influence of perceived distributive justice

\begin{tabular}{lllrrrr}
\hline & & Estimate S.E. C.R. P-value \\
\hline Post-recovery satisfaction $<---$ & Distributive justice & .48 & .04 & 12.27 & $<.001$ \\
Post-recovery satisfaction $<---$ & Gender & 1.25 & .25 & 4.86 & $<.001$ \\
Post-recovery satisfaction $<---$ & Age & 2.83 & .29 & 9.75 & $<.001$ \\
Post-recovery satisfaction $<---$ & Income & 2.71 & .31 & 8.80 & $<.001$ \\
Post-recovery satisfaction $<---$ & Travel frequency & -.39 & .14 & -2.78 & .005 \\
\hline
\end{tabular}




\section{DISCUSSION}

The research question sought to empirically examine the effect of perceived distributive justice of service recovery on post recovery satisfaction among domestic airline customers in south west Nigeria. Structural Equation Modeling was used to test the hypothesis. The outcomes show that perceived distributive justice was significant on post-recovery satisfaction $(\beta=.27, p<.001)$. Specifically, an increase in perceived distributive justice predicted an increase in post-recovery satisfaction. The control variables, gender $(\beta=.10, p<$ $.001)$, age $(\beta=.22, p<.001)$, income $(\beta=.18, p=.009)$ and travel frequency $(\beta=-.06, p=$ $.005)$ were significant on post-recovery satisfaction. Specifically, being a female, older, having a higher income and lower travel frequency were associated with post-recovery satisfaction. The model explained $25 \%$ variance in post-recovery satisfaction.

This finding corroborates the findings of a number of empirical studies such as McCollough (1995), Mauro, et al (2017), Oswald (2018), Stratemeyer, et al (2014), wherein a strong positive relationship was found between perceived distributive justice and customer satisfaction. According to McCollough (1995), recovery can partially mitigate the dissatisfaction which results from service failures. The results indicated that given failure, satisfaction was very strongly related to the superiority of the recovery effort. The study showed that the higher the recovery, the higher the satisfaction evaluation and service quality attitudes. The general model of recovery in the study predicted that distributive justice have a greater effect on satisfaction. The finding also goes the line of Stratemeyer et al (2014) who posited that a strong relationship exists between service recovery efforts and customer satisfaction. This study similarly confirm the finding of Blodgett et al, (1997) who say that material compensation is important to return dissatisfied customers back to a state of satisfaction during failure encounter.

\section{CONCLUSIONS}

This study investigated perceived distributive justice of service recovery and posts recovery satisfaction, a study of airline customers in the south west geopolitical zone of Nigeria. To this end, three dimensions of perceived justice of service recovery were sampled based on the revealed literature and the researcher's interaction with airline customers during the study. The study examined the influence of perceived distributive justice (independent variables) on post recovery satisfaction (dependent variable) The research objectives have been achieved since reliable, explicit, rigorous and unambiguous answers have been reasonably provided to each of the research questions in the study.

Conclusion is hereby drawn that perceived distributive justice of service recovery has positive and significant influence on post recovery satisfaction in the study area.

\section{RECOMMENDATIONS}

Airline companies operating in the zone should organize regular training programmes for their staff on how to work with emerging aviation technologies so as to minimize errors and reduce costs that are associated with compensation. They should make the training of their 
staff regular so that they will know and ascertain the cost benefit analysis of their actions during service delivery. They should also put in place regular inspection and rectifying measures to correct service related problems, matching their services with customers' needs and correct discrepancies (if any).

\section{REFERENCES}

Adams, J.S. (1963). Toward an understanding of inequity, Journal of Abnormal and Social Psychology, 67 (5), 422-436.

Adams,s J. (1965). Inequity in social exchange. Advances in Experimental Social Psychology, 62(1), 335-343.

Ahmad, F., Ghazali, H., and Othman, M. (2013). Customers preferences between fast food restaurants and casual dining restaurants: a conceptual paper. $3^{\text {rd }}$ international conference on management ( $3^{\text {rd }}$ icm 2013) proceeding, Penang, Malaysia, 10-111 June 2020. Retrieved from: www.internationalconference.com.my.

Battaglia, D., Borchardt, M., Afonso Sellitto, M., and Medeiros Pereira, G. (2012). Service recovery: a method for assessing performance, Business Process Management Journal, 18(6), 949-963. http://dx.doi.org/10.1108/14637151211283366.

Blodgett, J.G.; Donna J. H., and Tax, S. S. (1997). The effects of distributive, procedural and interactional justice on post complaint behavior, Journal of Retailing, 73(2), 185-210.

Boshoff, C. (1999). RECOVSAT: An instrument to measure satisfaction with transactionspecific service recovery. Journal of Service Research , 1 (3), 236-249.

Carew, F. (2010). The winning formular for nigerian fast food players consulting. choi-0810FC.

Choi, B. and La, S. (2013). The impact of corporate social responsibility (csr) and customer trust on the restoration of loyalty after service failure and recovery, Journal of Services Marketing, 27(3), 223-233.

Conlon, D., and Murray, N. (1996). Customer perceptions of corporate responses to product complaints: the role of explanations, The Academy of Management Journal, 39 (4), 1040-1046.

Craighead, C. W., Karwan, K. R. and Miller, J. L. (2004). The effects of severity of failure and customer loyalty on service recovery strategies. Production and Operations Management, 13 (4), (Winter), 307-321.

Elliwati J., Purwanto, B.M., and Dhammesta, B.S. (2012). The effect of perceived justice on customer satisfaction in the service recovery context: testing mediating variables, Journal of Service Science, 5(2), 1-14.

Ennew, C., and Schoefer, K. (2003). Service failure and service recovery in tourism: a review of christel dehaan tourism and travel research institute, nottingham university Business School.

Gronroos, C. (2008). Service management and marketing: customer management in service competition, John Wiley and Sons Ltd, Chichester.

Hart, C., Heskett, J., and Sesser, W. J. (1990). The profitable art of service recovery. Harvard Business Reviews , 68 (4), 148-156.

Jones, H., and Farquhar, J. (2007). Putting it right: service failure and customer loyalty in UK Banks, International Journal of Bank Marketing, 25(3), 161-172. 
Kim, T, Kim, W. G., and Kim, H. (2009). The effects of perceived justice on recovery satisfaction, trust, word-of-mouth and revisit intention in upscale hotels, Tourism Management, 30, 51-62.

Komunda M and Osarenkhoe, A. (2012). Remedy or cure for service failure? effects of service recovery on customer satisfaction and loyalty; Business Process Management Journal 18(1) 82-103.

Ladele, M. (2012). What are the impacts of fdi inflow on economic growth of emerging economics? (a look at brics)," M. Sc. thesis, submitted to the department of Economics, University of Hulls, UK.

Lee, E., and Park, J. (2010). Service failures in online double deviation scenarios: justice theory approach, Managing Service Quality, 20(1), 46-69.

Managing Service Quality, 18(3), 212-224.

McColl-Kennedy, J R. and Beverley, A. S. (2003). Application of Fairness Theory to Service Failures and Service Recovery, Journal of Service Research, 5(3), February, 251-266.

McCollough, M A.; Berry, LL and Manjit, S. Y. (2000). An empirical investigation of customer satisfaction after service failure and recovery, Journal of Service Research, 3(2), November, 121-137.

Michel, S. (2001). Analysing Service Failures and Recoveries: A Process Approach, International Journal of Service Industry Management, 12(1), 20-33.

Miller, J., Craighead, C., and Karwan, K. (2000). Service recovery: a framework and empirical investigation, Journal of Operations Management, 18(4), 387-400.

Nikbin, D., Ismail, I., Marimuthu, M., and Jalalkamali, M. (2010). Perceived justice in service recovery and recovery satisfaction: the moderating role of corporate image, International Journal of Marketing Studies 2(2)

Okeke, T. C; Olise, M.C. and Eze, G.A (2012). Research methods in business and management science, ( ${ }^{\text {nd }}$ Edition), Enugu, Iyke Venture Publications.

Othman, Z., Zahari, M., and Radzi, S. (2014). Customer behavioural intention: influence of service delivery failures and service recovery in malay restaurants, social and Behavioural Sciences, 105(1), 115-121.

Park, G., Kim, K., and O’Neill, M. (2014). Complaint behaviour intentions and expectation of service recovery in individualistic and collectivistic cultures, International Journal Of Culture, Tourism And Hospitality Research, 8(3), 255 - 271.

Philips Consulting (2015). The 2015 domestic aviation industry: customer satisfaction survey report.

Piyali, P. (2011). Customer retention through service recovery, International Journal of Research in Commerce and Management 2(12).

Solomon, M. R. (2004). Consumer behavior: buying, Having and Being, 6th edition, New Jersey: Pearson Education, Inc.

Sparks, B., and McColl-Kennedy, J. (2001). Justice strategy options for increased customer satisfaction in a services recovery setting, Journal of Business Research, 54(3), 209-218.

Sparks, B., and McColl-Kennedy, J. (2001). Justice strategy options for increased customer satisfaction in a services recovery setting, Journal of Business Research, 54(3), 209-218.

Stratemeyer, A. W., Geringer, S. D. and Canton, A. (2014). An exploratory investigation of the effects of service failures and recovery efforts on customer satisfaction. American Journal of Management. 14(3), 20-28. 
Tsai, C, Yang, Y., and Cheng, Y. (2014). Does relationship matter, customer response to service failure, Managing Service Quality, 24(2), 139 - 159.

Varela-Neira, C., Vasques-Casielles, R. and Iglesias, V. (2010b). The effects of customer age and recovery strategies in a service failure setting, Journal of Financial Services Marketing, 15(1), 32-48.

Varela-Neira, C., Vazquez-Casielles, R., and Iglesias, V. (2010a). explaining customer satisfaction with complaint handling, International Journal of Bank Marketing, 28(2), 88-112.

Wang, C., and Mattila, A. (2011). A cross-cultural comparison of perceived informational fairness with service failure explanations, Journal of Services Marketing, 25(6), 429 439.

Zemke, R., and Bell, C. (1990). Service recovery: doing it right the second time, training, Journal of Quality Management, 27(6), 42-48. 